This item was submitted to Loughborough's Research Repository by the author.

Items in Figshare are protected by copyright, with all rights reserved, unless otherwise indicated.

\title{
Beyond ConCA: Rethinking causality and construction accidents
}

PLEASE CITE THE PUBLISHED VERSION

https://doi.org/10.1016/j.apergo.2018.06.001

\section{PUBLISHER}

(c) Elsevier

VERSION

AM (Accepted Manuscript)

\section{PUBLISHER STATEMENT}

This work is made available according to the conditions of the Creative Commons Attribution-NonCommercialNoDerivatives 4.0 International (CC BY-NC-ND 4.0) licence. Full details of this licence are available at: https://creativecommons.org/licenses/by-nc-nd/4.0/

\section{LICENCE}

CC BY-NC-ND 4.0

\section{REPOSITORY RECORD}

Harvey, Eleanor, Patrick Waterson, and Andrew R.J. Dainty. 2019. "Beyond Conca: Rethinking Causality and Construction Accidents". figshare. https://hdl.handle.net/2134/33637. 


\title{
Beyond ConCA: Rethinking Causality and Construction Accidents
}

Eleanor J Harvey Human Factors and Complex Systems Research Group. Loughborough University, Loughborough, Leicestershire, LE11 3TU, UK. E.J.Harvey@lboro.ac.uk

Patrick Waterson Human Factors and Complex Systems Research Group, Loughborough University, Loughborough, Leicestershire, LE11 3TU, UK. P.Waterson@lboro.ac.uk

Andrew R. J. Dainty School of Architecture, Civil and Building Engineering, Loughborough University, Loughborough, Leicestershire, LE11 3TU, UK. A.R.J.Dainty@lboro.ac.uk

\begin{abstract}
The construction industry takes an orthodox approach to safety: Finding root causes, quantifying risk, and often blaming frontline workers. However, safety has reached a plateau and the limitations of this approach are starting to be acknowledged. A sociotechnical systems approach (as applied in the ConCA model) presents new opportunities to understand accident causation by linking immediate accident circumstances with the distal shaping and originating influences.

32 construction safety managers, consultants, and experts contributed their views regarding the hazards of construction (both human and physical) and the difficulties managing these. The findings provide an insight into the work of construction safety managers and their decision making which is influenced by industry-wide pressures and worker attributes over physical hazards.

Construction suffers from a wide range of pressures; a combination of both top-down, from the client, and bottom-up challenges from the workforce it attracts. The original ConCA model has been revised to reflect the findings. By applying systems thinking, the relationships between negative perceptions of workers' risk-taking and these challenges can be crystallised. The results support integrating safety into primary activities to increase engagement, learning legacies to transfer knowledge between projects, multidisciplinary teams to raise risk awareness, empowerment to combat their feelings of dissatisfaction and disloyalty, and collaboration in risk management to incorporate workers' expertise and ensure they feel valued.
\end{abstract}

Keywords: Construction, safety, sociotechnical systems 


\section{Beyond ConCA: Rethinking Causality and Construction Accidents}

\section{Introduction}

Fatality rates in construction are three times higher than the average across all industries 1.94 per 100,000 workers compared to 0.46 across all sectors in the UK (HSE, 2016) and 10.1 compared to 3.4 in the US (Bureau of Labor Statistics, 2015). The sector contributes substantially to the total number of occupational fatalities worldwide: $31 \%$ in the UK (HSE, 2014), 18.9\% in the US (NIOSH, 2011) and 20.9\% in the EU-28 (Eurostat, 2016). Over the last century these statistics have improved significantly, yet progress has plateaued in recent years (Bureau of Labor Statistics, 2015; HSE, 2014). Disillusionment with normative safety culture programmes (Guldenmund, 2010; Long, 2012; Sherratt and Dainty, 2017) and bureaucratic safety management systems (SMS) (Bieder and Bourrier, 2013; Dekker, 2014) is growing. Dekker and Pitzer (2016) claim these traditional forms of safety will never reduce accidents to zero because the methods themselves overcomplicate matters and draw focus onto trivial risks, leaving organisations vulnerable to catastrophic and highly improbable ‘black swan’ (Taleb, 2008) events.

Although construction's orthodox approach to safety may go some way to explaining this decline in safety improvement, progress is also hindered by the project-based nature of the industry which requires a dynamic and decentralised network of organisations (Lingard and Rowlinson, 2005). Building for a client means designs are unique, profit margins are low, and work is suited to a loosely coupled and dynamic network of specialist organisations contracted to specific aspects of the build. The temporal nature of work and contracts attracts uncommitted and low-skilled workers; subcontracting limits investment in training and safety management; financial constraints do not allow for contingencies or new ideas; learning is rarely transferred between projects; and the culture of litigation, blame and intolerance stifles progress (Harvey et al., 2016a). These difficulties of managing complexity, inconsistency and conflicts of interest in these temporary multiple organisations have long been recognised (Stringer, 1967)

This type of organisation presents many obstacles for management, learning, and innovation, and as such construction relies on a traditional stance of safety-by-compliance. Its philosophy is based on finding the 'root cause' of accidents, quantifying risk, and reducing it through technological and administrative interventions. In contrast, contemporary safety paradigms 
encourage a holistic view of jobs, work, and systems (Hale and Hovden, 1998; Wilson, 2014) and a humanistic view - focussing on ensuring safe operations, rather than preventing unsafe ones - and seeing people as a valuable source of responsiveness and resilience, rather than a liability to be constrained (Hollangel, 2014). For safety in construction to continue to improve, developing this type of approach could benefit the sector; however, others have questioned whether these new concepts are applicable (Harvey et al., 2016b) or necessary (Lingard, 2013).

\subsection{Sociotechnical systems and systems thinking}

Sociotechnical Systems (STS) theory developed in the 1950s and originally focussed on the impact of technology at work, but has also been applied to risk, health, safety, and accidents (Waterson et al., 2015). This era introduced a shift away from traditional perspectives on human error towards a more naturalistic and contextualised approach "to provide a 'holistic' assessment of work-system interfaces and to capture the interaction between these" (Waterson et al., 2015). STS sees humans as assets and technology as a tool, and emphasises quality of life, respect for individual differences, and respect for stakeholders (Eason, 2008; Read et al., 2015).

The role of social and cultural factors in accidents has been recognised for over 30 years (Pidgeon and O’Leary, 2000; Turner and Pidgeon, 1997), as well as political, economic, legislative and regulatory influences. Fundamental to an STS approach to risk management is the belief that accidents "are not only caused by direct physical events, nor by human errors alone. They have their roots in organisational settings and in the sociotechnical system companies are active in" (Swuste, 2008). Therefore, when considering the role of humans in accidents, a systems focus is vital - taking account of context, interactions, complexity, emergence and alternative perspectives (Wilson, 2014).

\subsection{Systems thinking in construction}

There have been calls for construction to move away from a 'root cause' mentality towards accidents since the turn of the millennium (Gibb et al., 2001). Several studies looking into the factors affecting performance on construction sites emphasise managing safety at every level of the system (Sawacha et al., 1999); In particular, the Construction Accident Causation (ConCA) model promotes a holistic view of incidents (Haslam et al., 2005). The model shows the relationships between the immediate circumstances causing an accident, and the factors which shape and originate it - following in the footsteps of Reason's 'Swiss Cheese' 
metaphor (Reason, 2000) (Figure 1). It demonstrates the requirement for a collaborative effort to own and manage risk from the client team, concept designers, project management, preconstruction planners and the industry as a whole, and to ensure risk management robust, integrated and participatory (Gibb et al., 2006).

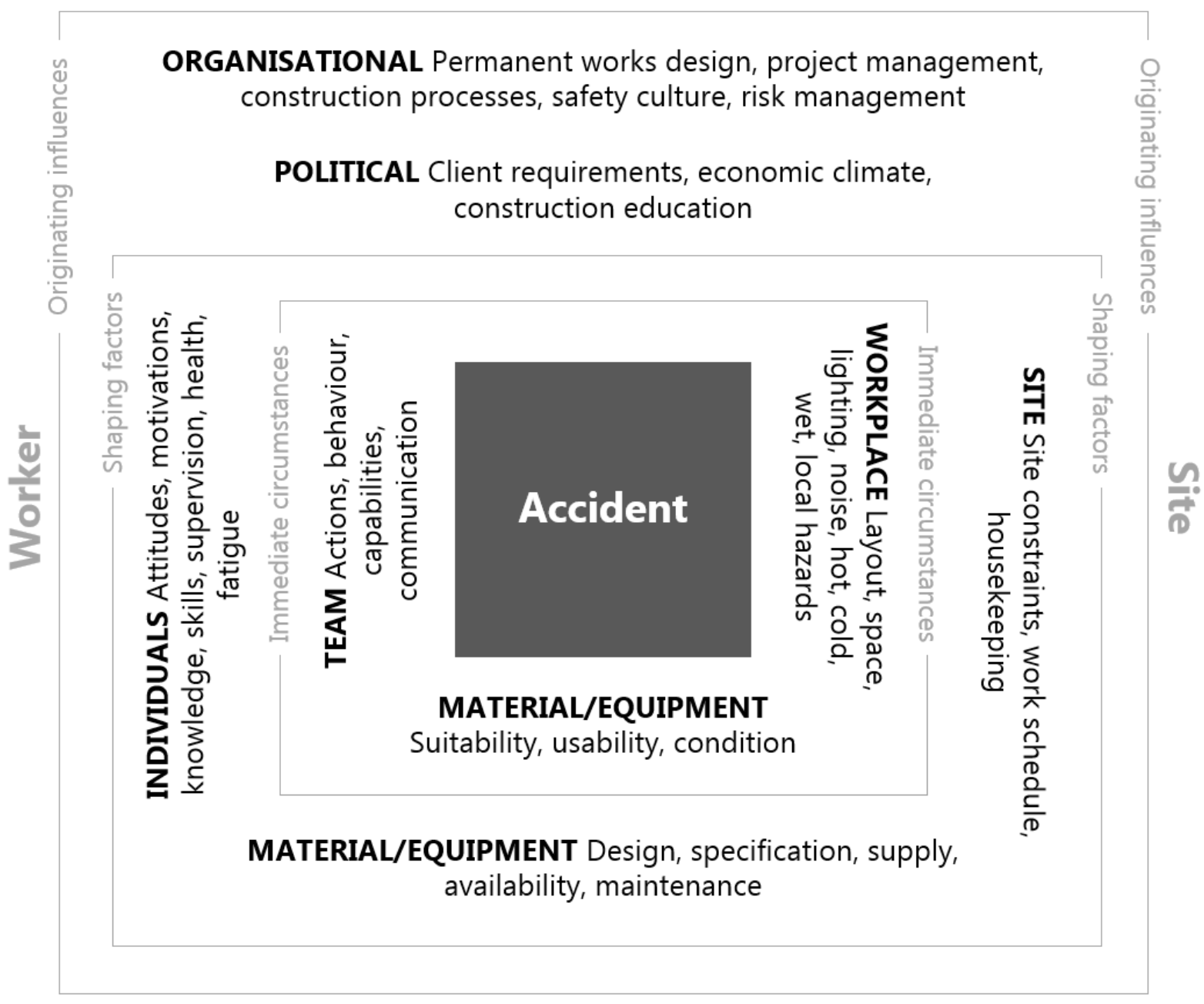

\section{Technology}

Figure 1 - The ConCA model (Haslam et al., 2005)

An integrated approach has been shown to support project success (Franz et al., 2017), organisational learning (Behm and Schneller, 2013), the relationship between designers and constructors, (Atkinson and Westall, 2010), teamwork between trades (Baiden and Price, 2011) and safety leadership, by developing trust and communication throughout the system (Donovan et al., 2016). Systems thinking has been applied to demonstrate the emergence of events, such as why safety outcomes are often inconsistent with inspection results (Saurin, 2016) or supposed leading indicators (Lingard et al., 2017). However, a need for further research into systems thinking in construction has been recognised (Love et al., 2016); While 
in other sectors systems models have progressed and developed, ConCA remains the best fit for construction.

The existing literature on systems dynamics modelling in construction often takes a 'hard' (Scholz and Tietje, 2002, p. 120) or objective approach to modelling the complexity of construction organisations and performance, based on data mining of accident reports (Chi and Han, 2013), existing literature (Shin et al., 2014), or simulations (Goh and Askar Ali, 2016). Conversely, literature on risk management and risk-taking focuses on the range of proximal and distal factors which predispose workers to these behaviours (Choudhry and Fang, 2008; Oswald et al., 2014) but rarely explore the relationships between these and where they originate from (Asilian-Mahabadi et al., 2014).

\subsection{The present study and organisation of the paper}

The aim of this study was to review the credibility of the ConCA model with a panel of expert interviewees. Their perception of the system, the pressures they face, and the factors which shape their decision-making and leadership style were discussed and mapped onto the original framework. This included the intrinsic hazards of the building process, the workforce, and the wider system. These data were used to crystallise relationships between these factors and substantiate the systemic nature of accident causation.

The findings are presented as 2 sections. First looking bottom-up at the nature of work and the workforce, then looking top-down at the organisational and industrial challenges. The discussion brings these together drawing out 5 key themes, or common perceptions of workers, and exploring their systemic origins. Finally, a developed and updated version of the ConCA model is proposed which gives a fuller picture of accident causation.

\section{Method}

\subsection{Study design}

Occupational Safety and Health (OSH), ergonomics, built environment, and STS are all research fields which have been said to take an overly pragmatic approach to research (Dekker et al., 2012; du Toit and Mouton, 2012; Shannon et al., 1999; Waterson et al., 2015). A qualitative approach is advocated to gain a deeper understanding of the social phenomena involved - in this case decision making and risk-taking. In particular, interviewing was chosen as it gathers meaning-laden and contextualist data to explore and make sense of these constructs. 
A draft protocol was developed based on investigators notes from a focus group with 14 participants who discussed the key issues facing safety and health in construction projects. This ensured the scope of the questions would cover a sufficient breadth of human and technical factors at all levels of the system, in accordance with STS theory. The questions were chosen to gain an in-depth understanding the role of those managing risk in construction with each question focussing on a different facet - hazards, challenges, workers' attitudes, and factors contributing to unsafe acts. This was piloted with 1 participant to confirm the questions and probes were thought-provoking and the responses relevant and valuable. The final semi-structured interview protocol was designed comprising of 5 questions (Appendix 1).

Limiting the questions to a loose schedule helped to achieve a 'rich' (dense and meaningful), saturated dataset focussed on these areas of interest (Guest et al., 2006), which in turn maximises the potential to find meaning (Onwuegbuzie and Leech, 2005). However, a semistructured design was chosen as it allows a balance between gathering rich and focussed data and keeping the feel open and conversational; this builds rapport between the participant and investigator, encouraging them to share stories and examples from their own experience (Rabionet, 2011). A semi-structured design also supports probing or following-up responses to understand their meaning (Given, 2008) which is important given the exploratory research question.

\subsection{Participants}

Participants were recruited through the researchers' contacts and snowballing the invitation to participants’ colleagues. Judgement sampling was applied (based on occupation and experience) to create a sample of construction safety experts with maximum variation within this inclusion criterion; this included those involved in different roles within the risk management process - such as research, policy-making, training, and consultancy, as well as frontline managers - from a range of organisations. The sample included predominantly safety managers working for (or having previously worked for) construction, infrastructure, architecture, and civil engineering companies. These were global or multinational tier-1 suppliers (in direct contact with the client) headquartered in the UK, US or EU, and employing between 4,000 and 48,500 employees. All the participants had at least 5 years' experience working on or researching large projects with a strong commitment to safety. The mean (SD) experience of participants was 22.45 (13.24) years. This does not include previous 
experience working in health and safety in sectors other than construction which they drew on for comparison.

Table 1 - Study participants and their roles

\begin{tabular}{|c|c|c|c|}
\hline Role & $\begin{array}{c}\text { Pilot Focus } \\
\text { Group }\end{array}$ & $\begin{array}{c}\text { Pilot } \\
\text { Interview }\end{array}$ & $\begin{array}{l}\text { Recorded } \\
\text { Interview }\end{array}$ \\
\hline Health and safety manager or director & 9 & & 10 \\
\hline Health and safety training coordinator & 1 & & 1 \\
\hline Construction manager & 1 & & 1 \\
\hline Self-employed risk consultant & 2 & & 3 \\
\hline Academic with previous employment in construction & 1 & & 6 \\
\hline Academic researching construction safety & & 1 & 4 \\
\hline 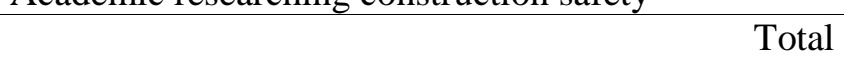 & 14 & 1 & 25 \\
\hline
\end{tabular}

The specialised inclusion criteria increased the chances of reaching data saturation, but its internal diversity also ensured as many present themes as possible were captured (Guest et al., 2006). Data collection ended when 'data saturation' was reached and no novel codes were added to the coding structure during analysis (Glaser and Strauss, 1967). 53 potential participants were contacted yielding 25 recorded interviews (Response rate 47\%). 8 participants from the pilot focus group went on to participate in a recorded interview; they were not counted twice, leaving 6 plus 25 and one pilot interviewee, giving a total of 32 individuals contributing to the dataset.

\subsection{Data collection}

Interviews were conducted between October 2015 and January 2016 by telephone $(n=15)$, Skype $^{\mathrm{TM}}(\mathrm{n}=1)$, and in person $(\mathrm{n}=9)$ depending on the most convenient method for the participant. All the interviews were conducted by a single investigator. The duration of the recordings ranged from $20 \mathrm{~min}$ to $60 \mathrm{~min}$, with an average of $37 \mathrm{~min}$.

\subsection{Analysis}

The recorded interviews were transcribed verbatim and the complete dataset contained 140,000 words. All coding was completed by the same investigator to ensure consistency. Open coding was used to assign a theme to each sentence, taking an inductive approach to categorising trends. The codes identified were reduced by grouping similar and redundant themes into an axial or tree structure and opening up dense codes to develop their subthemes. Unlike induction or deduction - best used either in unresearched territories or to test theories respectively (Bryman, 2012; Walliman, 2011) - abduction (Dubois and Gadde, 2002) describes a process whereby empirical observations are used to refine a proposed 
framework and coproduce knowledge (Green et al., 2010) - in this case further developing the ConCA model (Haslam et al., 2005).

\section{Findings}

\subsection{Hazards in construction}

The initial questions sought to extract the problems and pressures of the construction industry which make risk difficult to manage. Participants' responses to these two questions often provided overlapping content, demonstrating the interwoven nature of hazards and validating the use of STS analysis to understand this complex system. The interaction between the intrinsic hazards of construction and the risks caused or exacerbated by poor management was most clearly demonstrated by the participants who questioned whether describing construction as hazardous was correct and instead felt poor management (of risks and the project as a whole) was at fault.

I don't think construction is dangerous, I think what's dangerous about construction is not truly understanding the hazards that construction presents, and therefore not evaluating the risks associated with those hazards, not properly designing out hazards. Safety Manager

\section{Intrinsic hazards involved in construction work}

17 themes were extracted which relate to the intrinsic hazards of the construction process, as opposed to management issues which interact with these or introduce their own risks. These are illustrated as a tree diagram in Figure 2. The number in brackets following each subject in the figures show the number of responses including that theme. These numbers are aggregated into high-level themes, where the same participant is only counted once, but which also include responses from other participants about the overall topic that could not be subcategorised. 


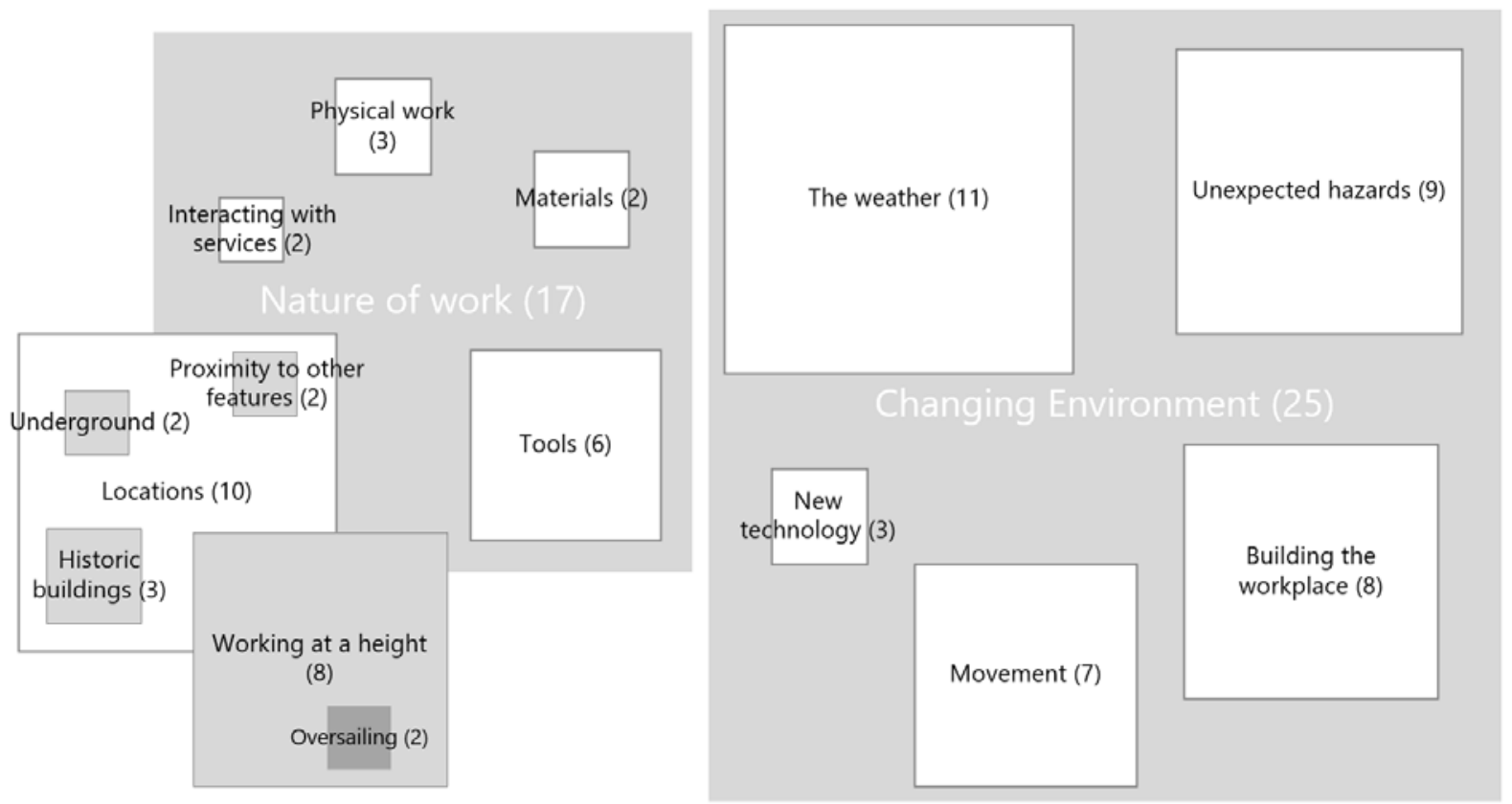

${ }^{1}$ Figure 2 - The intrinsic hazards involved in construction processes

Features of construction process such as dangerous materials, tools and the physical nature of work were identified, as well as the hazards of building within a context of physical geography and existing infrastructure. Working at a height was also a recurring theme which reflects its importance as one of the major causes of fatalities (HSE, 2014). Nevertheless, these physical hazards were overshadowed by the changing nature of construction projects, the effects of which were universally recognised. This included both external changes, such as weather and unanticipated hazards of the site, and internal changes as the workplace grows and materials are transported.

The biggest thing about construction is that it's permanently temporary until the day we finish, and everything changes all the time, even the things you've done the same are different. Safety Manager

Walls go up and so all of a sudden our fire escape routes need to change, or we've dug a trench across the- the ground and now we have to change our whole traffic management system. Risk Consultant

As well as physical hazards within a changing environment, many participants chose to discuss the way these hazards are exacerbated, and other risks introduced, by industry and workplace factors. These are explored in 'Risk management difficulties'.

\footnotetext{
${ }^{1}$ The shading in Figures 2 to 4 is to improve readability and carries no meaning.
} 


\section{The construction workforce}

The intrinsic hazards of the construction process would not have such potential for harm if not for the proximity of the workforce within these activities.

You've got machinery and humans together which as we know is a terrible mix ... in a factory hopefully either the machinery's moving and the people are stood still or vice versa, we've got both happening at the same time! Construction Manager

Undoubtedly, people play a role in creating risk in construction; it is human nature to be variable, unpredictable, prone to error, and to struggle with change, but there are many factors which make those attracted to work in construction - typically young, agile, men particularly susceptible to unsafe acts. Table 2 is a matrix which compares demographics of the construction workforce with common traits that were seen to increase their propensity to take risks. The shading shows where participants drew links between the characteristics of the workforce and these demographics - dark for a strong association, and light for possible. As with figure 2, the numbers in brackets represent the number of respondents who spoke about each characteristic.

Table 2 - Demographics of the construction workforce which exacerbate risk taking behaviours

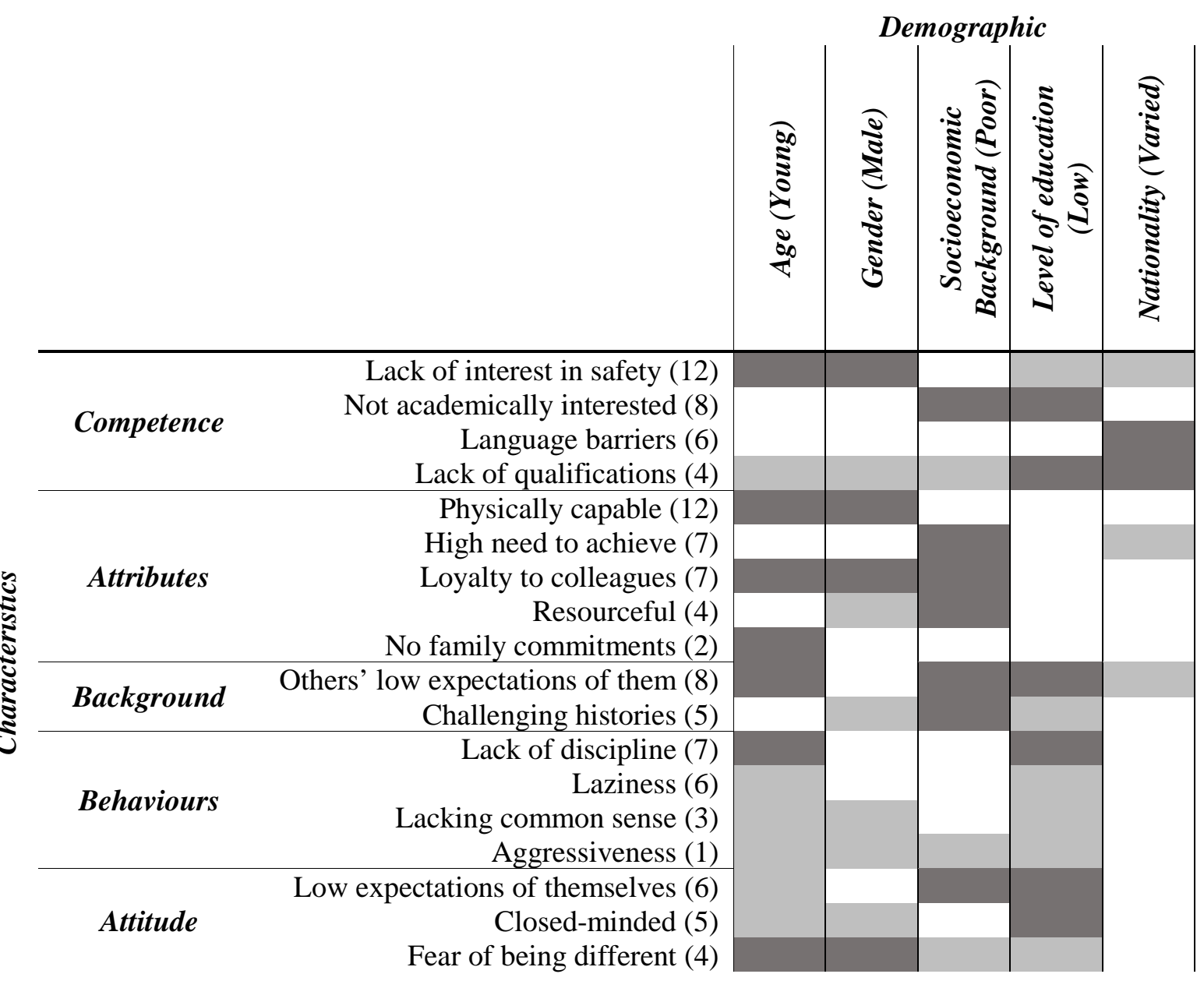


The requirements for education and language skills are low, and the short-term contracts provided by project-based work are appreciated by workers who are young and free from responsibilities, and therefore able to work long hours and travel. Construction workers are known for being tough and physically capable, but this can cause workers to push themselves beyond safe (and healthy) limits because they believe they are fit, strong, flexible, and have good balance and stamina enabling them to cope with the tasks.

Many of the factors in Table 2 lead workers to engage in risk denial: The male-dominance of the industry pushes workers to show they are able to cope with its risks; economic disadvantage means workers act to cut-corners and save money; age can mean workers are complacent based on their physical capability (young) or experience (older); and workers with low academic attainment are less likely to fully understanding the risks. The diversity of nationalities working in construction is also a demographic of the workforce which exacerbates risk taking behaviours, although rather than the denial of risk, this can be attributed to misunderstandings due to language barriers, different expectations of OSH, and a lack of standardised international qualifications.

Unfortunately, the type of work attracts workers with traits which, while desirable from a production perspective, mean they can be unpredictable, complacent and prone to risk-taking. Positive attributes such as being hardworking, innovative, and free from commitments can have a negative impact on judgement.

One worker actually said to me: "If I die, my parents are the only ones that are gonna miss me." Academic

This recklessness suggests workers lack an appreciation of their worth and their impact on those around them. The desire to be seen as a hard worker can be partially attributed to the importance of reputation for securing work in the industry, but can also be interpreted as a product of workers' backgrounds - low academic attainment and economic disadvantage. The low expectations held by others and of themselves fuel a strong need to achieve and be seen as helpful and resourceful.

In [area] we tend to be a bit poorer and we think a bit more creatively... 'cos they're trying to save money and we've gotta tell them that their safety- well we do tell them that their safety is much more important than any amount of money in the world. Training Coordinator 
Another reason why construction is risky is some people are very keen- which is an admirable traitvery keen to help others, and almost jump in when they can't- when they haven't got the competence to do that particular task, to try and help out. Safety Manager

Another trait mentioned by participants was a fear of speaking in public - a skill which is not important for construction work - but which, alongside peer pressure, can contribute to an unwillingness to report unsafe incidents. This lack of confidence combined with the low expectations, low sense of personal value, and a strong need to achieve suggest one factor contributing to construction workers' cavalier attitude to risk is a desire to prove they are capable.

\section{Construction workers' attitude towards risk}

Participants felt workers' attitudes varied significantly both between and within individuals depending upon the activities or circumstances, but overall were improving with time. Brace, Gibb, Pendlebury and Bust (2009) categorised attitudes to risks as "sensation seekers", deniers”, “acceptors” or “avoiders” (p.194). These are expanded upon based on participants' descriptions: A distinction was made between sensation deniers who are genuinely oblivious to the risks, and those who are aware yet deny a risk's potential for harm; a further distinction between sensation acceptors for whom this acceptance made them either more tolerant or more mindful of the risks; and the addition of a 'risk appreciators' category. These categories are described in Table 3 and Figure 3. 


\begin{tabular}{|c|c|c|c|}
\hline Attitude to risk & $\begin{array}{l}\text { Participants } \\
\text { stating workers } \\
\text { hold this attitude }\end{array}$ & Quotation & Description \\
\hline Risk Averse & 3 & $\begin{array}{l}\text { You've also got people who- perhaps towards- } \\
\text { later in their working careers are much more } \\
\text { risk-averse. ID } 5\end{array}$ & $\begin{array}{l}\text { A few construction workers, particularly older workers, are risk } \\
\text { averse. They are seen as a memorable exception to the norm } \\
\text { given the nature of the work. }\end{array}$ \\
\hline Risk Respecting & 6 & $\begin{array}{l}\text { Some accept it's just part of the environment, } \\
\text { but it can be managed effectively. ID } 3\end{array}$ & $\begin{array}{l}\text { Workers are aware of the risks and are pragmatic about risk } \\
\text { management. }\end{array}$ \\
\hline Risk Accepting & 6 & $\begin{array}{l}\text { The workers themselves are pretty aware of } \\
\text { the risks. Whether they do anything about it } \\
\text { I'm not quite sure! ID } 18\end{array}$ & $\begin{array}{l}\text { Workers are aware of the risks but these are normalised as part of } \\
\text { construction work. They become desensitised and are unlikely to } \\
\text { challenge unsafe conditions. }\end{array}$ \\
\hline Risk Denying & 10 & $\begin{array}{l}\text { Whilst these guys appreciate that there are } \\
\text { risks, he thinks "Hey, I can make } £ 25 \text { more for } \\
\text { less time!" and so that- so the risk in a sense is } \\
\text { almost carted. ID } 25\end{array}$ & $\begin{array}{l}\text { Workers are aware of the risks but deny their potential for harm } \\
\text { because their judgement is influenced by complacency or } \\
\text { conflicting priorities. }\end{array}$ \\
\hline Risk Oblivious & 11 & $\begin{array}{c}\text { I honestly don't think that they see the risk out } \\
\text { there. ID } 24\end{array}$ & $\begin{array}{l}\text { Workers are unaware of the risks they face. This could be due to a } \\
\text { lack of experience, competence, or training, and particularly } \\
\text { regarding the work of other trades which could interact with their } \\
\text { own. }\end{array}$ \\
\hline Risk Appreciating & 4 & $\begin{array}{l}\text { Construction workers actually like and } \\
\text { embrace risk, 'cos it's exciting, it's innovative, } \\
\text { it's dynamic. ID } 3\end{array}$ & $\begin{array}{l}\text { The risks and challenges of construction work are a significant } \\
\text { factor in workers' job satisfaction: They enjoy working in new } \\
\text { and varied environments, thrive on problem solving, and take } \\
\text { pride in facing challenges others might think too difficult. }\end{array}$ \\
\hline Risk Seeking & 3 & $\begin{array}{l}\text { My biggest worry would be with our young } \\
\text { people is that they do they think they're } \\
\text { immortal and they will try things. ID } 2\end{array}$ & $\begin{array}{l}\text { Some construction workers were actively 'risk seekers', but these } \\
\text { attitudes predominantly occurred among younger workers and } \\
\text { rare "mavericks" (Risk Consultant). }\end{array}$ \\
\hline
\end{tabular}




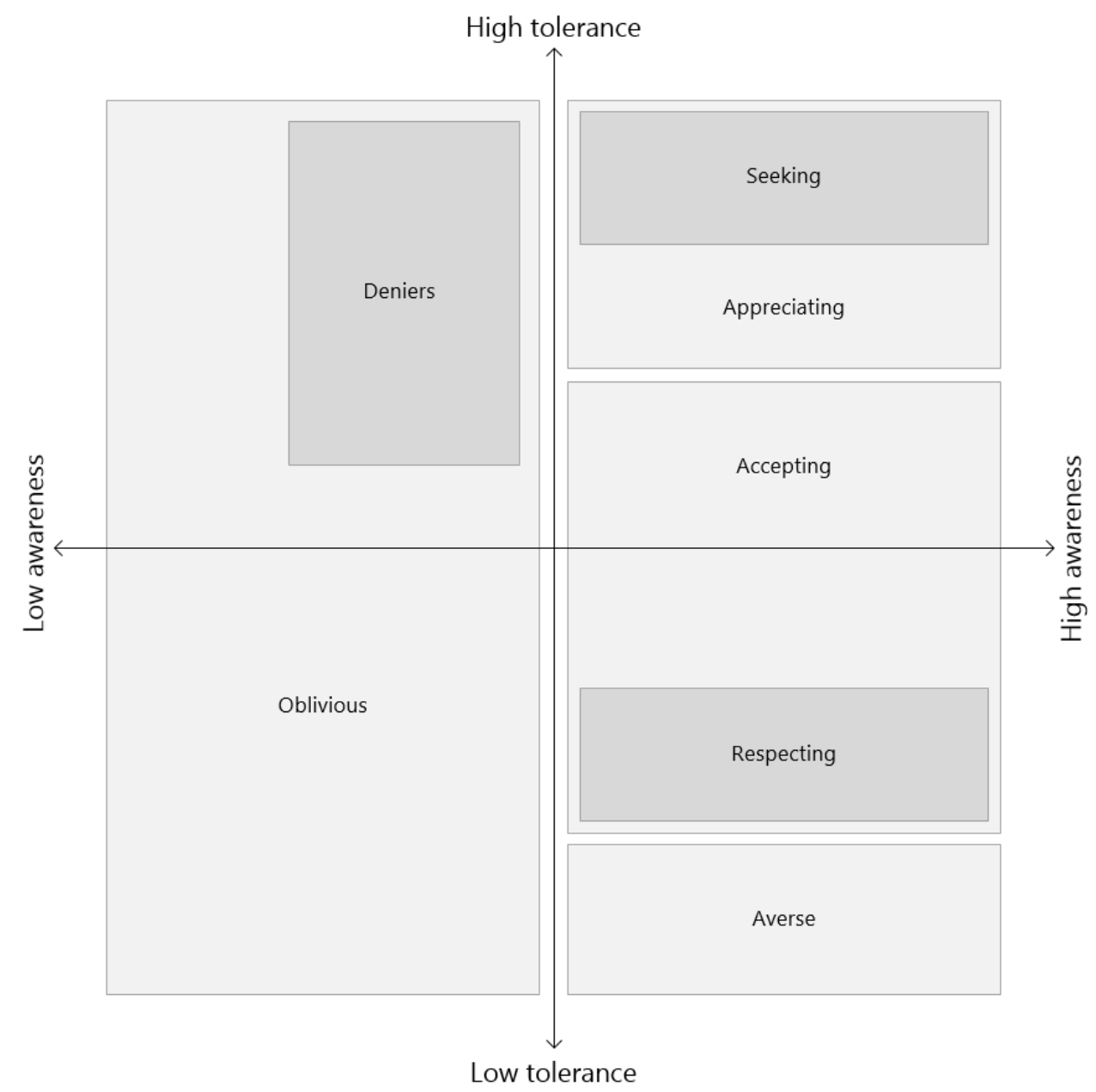

Figure 3 - Risk tolerance verses risk awareness of different worker attitudes

\section{Factors shaping the acceptability of risk}

The significant numbers who felt that construction workers were oblivious to risk, and many more who said they had a high tolerance or poor understanding of risk, prompted an in-depth analysis of the factors participants felt influenced this.

Complacency was a prominent theme, said to be caused by either experience or previous positive outcomes; familiarity with such situations; or distancing - an "it would never happen to me" mindset.

Other significant negative effects were attributed to a lack of competence or training about risk, and a poor or macho safety culture. Conversely, participants felt workers perceived the risks as less acceptable if they had experience of previous accidents, had commitments to family or friends and colleagues, management were committed to enforcing safety, and the location of work felt dangerous (e.g. underground or at sea). 
They've all sort of seen something they'd prefer not to...they turn round and think "Well hang on, the ambulance isn't gonna come toddling up the road, there isn't one" you know? So whatever happens you've gotta survive it for at least- well if you're off shore at least an hour. Risk Consultant

There were several factors which have potential to have either a positive or negative effect, such as peer pressure and previous experience of the construction industry, national culture, and age. Participants were evenly split as to whether older workers became more or less tolerant to risk with experience, and similarly participants felt younger workers were either aware of their lack of experience or thought they were invincible. Variability can also be seen within the international demographics of the construction industry: Workers who have been exposed to poor safety attitudes in other countries may have no concept of formal safety management systems, making them difficult to control, whilst other cultures take a rigid approach to rules meaning their obedience is advantageous for safety.

When the magnitude or consequence of a risk is perceived as high and uncontrollable, workers were said to be more cautious; however, this could also have a negative influence as serious risks such as high voltage current or working at a height can overshadow smaller risks making these seem more acceptable. Workers were thought less likely to perceive a risk if it was relevant to their trade, and they had therefore become complacent about it, or it was not relevant to their trade, and they did not understand it. This also meant workers were likely to only take ownership of risks relevant to their trade and compartmentalise their management.

Communication about risk management meant workers were more vigilant, but 4 participants said risk management measures had the potential to encourage tolerance because, in accordance with risk homeostasis theory (Adams, 1995; Wilde, 1982), workers feel the risks have been adequately controlled. Finally, if workers felt valued by management, that their skill was valuable, had recent training, or were trained in multiple trades they were less tolerant to risk. As seen in the previous section, attitudes to risk in construction are highly varied and subject to the complex interaction of many factors.

\section{Factors leading to unsafe acts}

Factors such as experience, training and culture, influence the acceptability of risk; however, participants also spoke of the pressures and distractions that could cause workers to behave unsafely, regardless of whether they felt the level of risk was acceptable. 


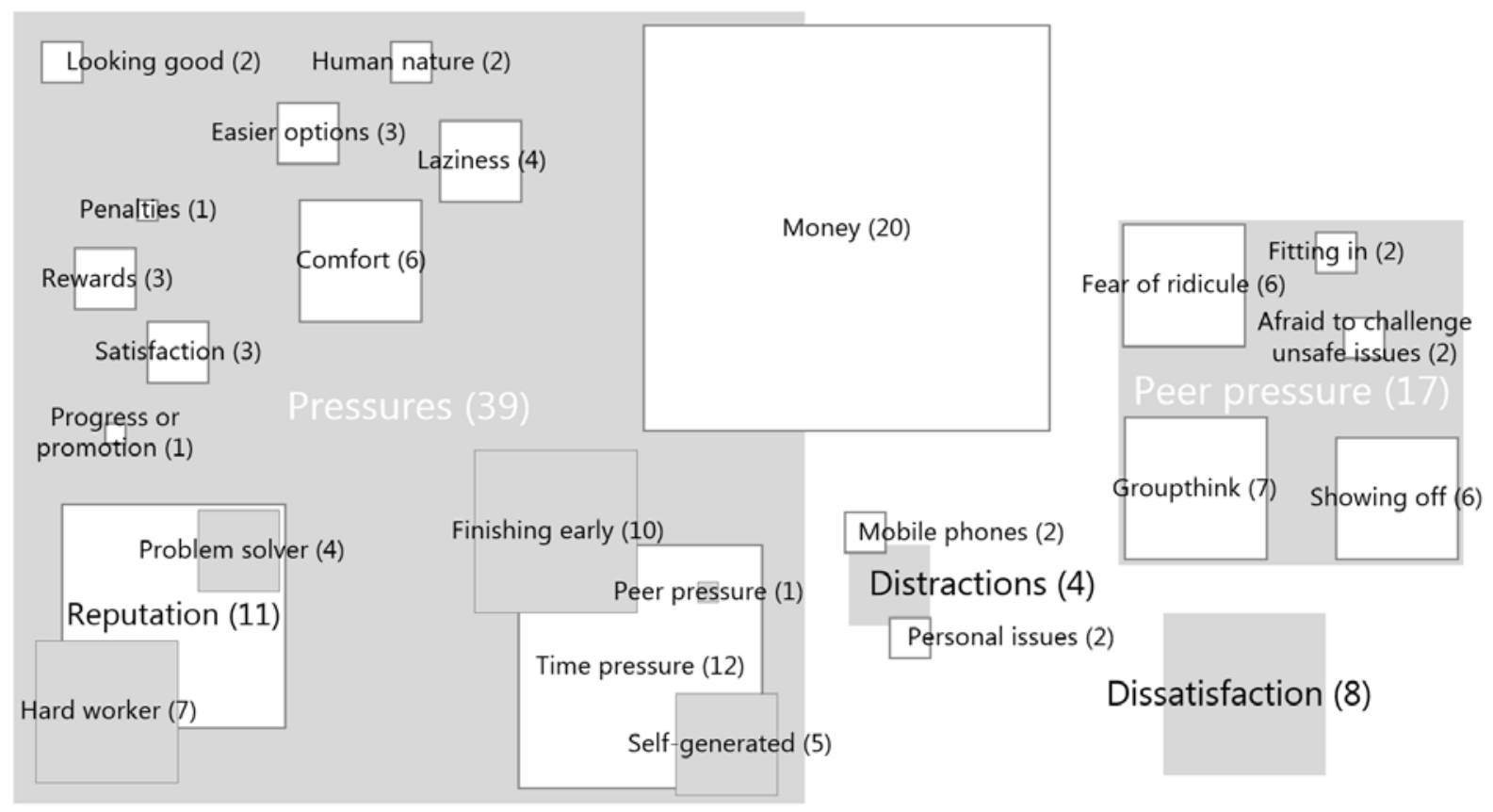

Figure 4 - Factors which can cause workers to make unsafe decisions

Whether or not a worker chooses to accept a risk depends upon its perceived benefits whether these are worth the risk (Adams, 1995; HSE, 2004). Figure 4 shows that participants felt workers were often motivated to take risks by money, peer pressure, time pressure, and concern for their reputation. As well as these trade-offs, some participants mentioned dissatisfaction as a motivation for unsafe acts, particularly where they felt restricted or patronised by safety measures, and a few said they would act unsafely if distracted by a mobile phone or personal issues.

The trouble is the workers will latch onto this [inappropriate safety measures] and see this as an inability of the management to be flexible, in what they're doing, and then they sort of rebel against that, and there is resentment and a negative attitude. Academic

Workers took unsafe actions because they were not aware of the risks themselves or their impact on others. In particular, workers were more likely to behave unsafely if they were not aware of the consequences of the risk and lacked knowledge or experience around it. More complex risks, where the hazard develops from combination of causes, and those outside a worker's trade were also likely to be missed.

Attitudes towards risks are an important consideration, but one of many factors which contribute to the decision-making process of weighing up knowledge and awareness of risk against pressures, priorities, and distractions. So far, unsafe acts have been discussed from an individual perspective - the factors that affect the acceptability of risk (Section 3.2) and decision-making (Figure 4) - however, these should be seen in the context of the wider 
system: Participants also spoke about many team, workplace and organisational influences which can affect someone's propensity to act unsafely and show the importance of not placing blame at the frontline.

To some extent the conflicting factors in Figure 4 can be seen as products of both the workforce and the industry: Time pressure may stem from a desire to finish early but also the client or poor planning; reputation is important to secure work in a competitive industry; poorly designed Personal Protective Equipment (PPE) is bulky, uncomfortable, and interferes with operations; showing off shows a desire to be accepted into a transient community; and being motivated by money is not only an individual trait but one which reflects the sector as a whole and companies' desire to stay in business. It is clear that sacrificing safety is not an individual's choice but a complex decision based on many pressures and issues.

\subsection{The wider challenges involved in managing risk}

Thus far, the intrinsic hazards of construction have been extracted, and aspects of the construction workforce which participants felt increased workers' propensity for risk taking behaviours. The remaining data related to other issues which made managing risk difficult in construction. These codes were grouped into a tree structure, ordered into a hierarchy of distance from the frontline based on ConCA (Originating Influences, Shaping Factors, and Immediate Circumstances) and ranked according to prevalence (Table 4). The relationships between these factors, and the site and workforce challenges already identified, are explored in section 4.2 of the Discussion. 


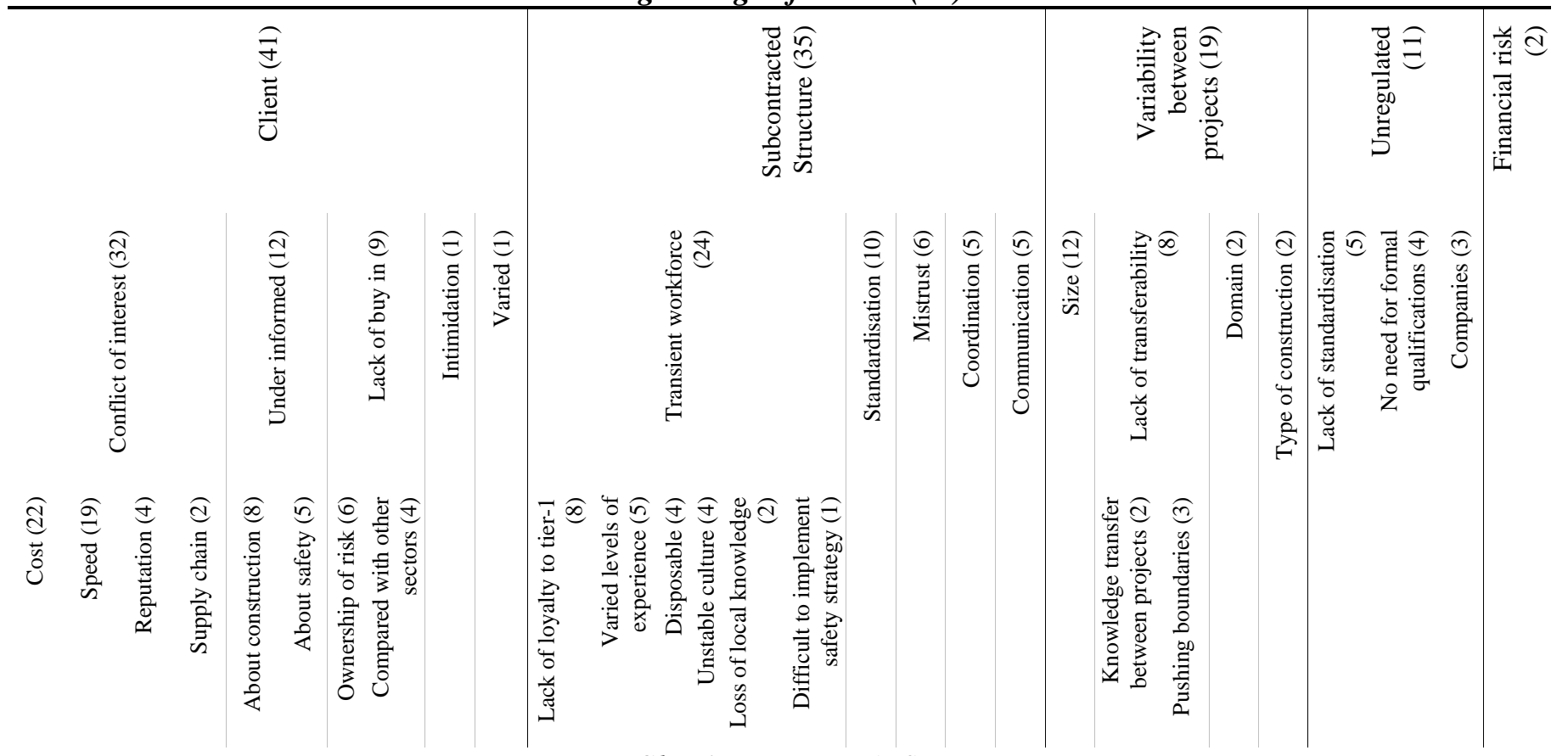

Shaping Factors (74)

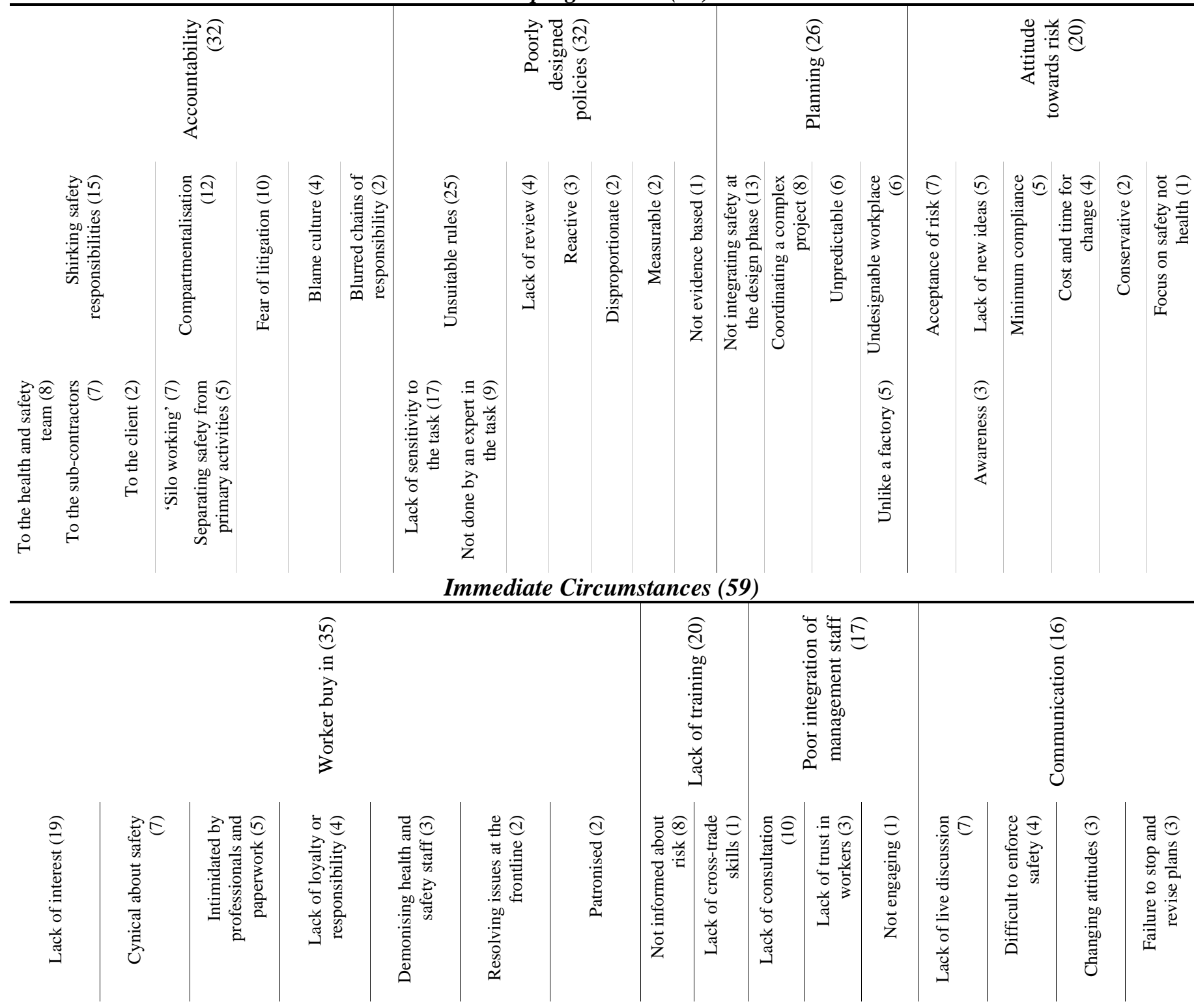




\section{Discussion}

The findings show the range of challenges that influencing decision making: Construction work is high-hazard in combination with constant change making risks difficult to control; the demographics of the workforce (young, male, international, and with low levels of education and economic privilege) are associated with characteristics that exacerbate risktaking behaviours; and the project-based, client-driven structure of the sector is competitive, unregulated and litigious.

Primarily, workers were seen as oblivious to the risks or tolerant and willing to deny the risk in the face of other priorities. However, a holistic or systems thinking approach to analysis helps to reveal the complex relationships between this and other immediate, shaping and originating causes of accidents - challenging the tendency to blame workers and look for a "root cause". The systemic origins of 5 worker attributes that were seen to cause accidents low engagement with safety, 'silo working', lack of competence 'cutting corners' and a high risk tolerance - are explored in the following section. The industry-wide factors which cause, attract, and exacerbate these behaviours demonstrate the value of systems thinking to address construction risks.

\subsection{Worker traits and their systemic origins}

\section{Low engagement with safety}

On the surface workers are seen to lack interest in safety and therefore fail to engage in risk management. However, this is a relationship which goes both ways: not only do workers fail to engage with management, but management fail to engage with the workforce. Although the workers are the experts in the task, it is presumed they are risk-takers who need to be controlled and this limits collaboration; thus, because their expertise is not valued, they disengage from the project. Many of the participants recognised the need for enhanced collaboration, but the project-based nature of the industry makes this difficult: Learning is disrupted in temporary organisations and there is limited time built into the schedule to gather input from the workforce during the design phase.

This lack of engagement means safety becomes an afterthought and policies are ill-suited to the context, making sweeping generalisations about the nature of construction work. Poorly designed procedures and equipment cause workers to become cynical and, again, disengaged because they feel they have little influence or value. They become disobedient (either as a pragmatic reality of getting work done or as an act of animosity), resentful of their 
employers, and demonise OSH - perpetuating the disconnect between workers and safety which is perceived as their lack of interest. This emphasises the importance of integrating safety into primary work activities so they suit the context and support, rather than hinder, efficient work.

It is clear some effort is needed to break the vicious cycle of managements' mistrust and rigid rules leading to workers' disengagement and disobedience. Although workers appear uninterested in safety, this could be because they are not given timely opportunities to engage, do not expect to be engaged with, or have become cynical about safety because their input is not valued. Rather than blaming workers' lack of interest, it is important to recognise the impact of this as well as peer pressure, fear of school-like situations, intimidation from professionals, cynicism, and a misperception of OSH staff as enforcers. Acknowledging these reasons for low engagement shows where interpersonal skills and guidance for engaging with workers could be developed and improved in light of this.

\section{'Silo working'}

Similarly, as a result of low engagement between workers and management, workers are seen to work in silos - compartmentalising their role and the risks associated with it.

When they're just treated as a part in a much bigger picture-jigsaw, and your part isn't that important- or that's how they perceive it perhaps, then their interest in that project and that organisation, and risk, is diminished. Academic

Workers contracted to do a specific task for a specified price rarely appreciate the significance of their role in relation to the project. Accidents can happen because they fail to see the 'big picture'; how their work might interact with other trades on site or the wider impact the risks they take could have. On one hand this could be seen as a lack of competence, but it is also indicative of problems within the project-based nature of construction: Projects need specific skills for certain periods of time and work to a tight schedule. Brief temporary contracts allow little time or incentive to invest in training, and workers are under pressure to finish their tasks and move on. The system is not set up to allow relationships between trades to develop and instead they become inward-looking, defensive, and isolated, which narrows their perception of risk.

Several participants felt that workers' perception of risk was higher if their trade was valued, particularly if their work was visible in the finished building, and they had an awareness they were contributing to something they could be proud of. Projects are more likely to be safe 
and successful if workers understand their role as part of a larger project, particularly if the project is high-profile (Bolt et al., 2012). Some participants also felt training workers in skills other than their own would help them to identify the hazards of other trades. However, although autonomy and job rotation have been shown to improve job satisfaction (Parker et al., 2017; Waterson, 2015), it would be difficult to justify and implement this in a transient environment where the skills required are highly specialised.

\section{Lack of competence}

Under the broad term of competence, participants referred to not only a lack of technical competence in one's own trade, but an awareness of safe practice, the work of other trades, and the interactions between site activities. This highlights the breadth of skills and traits needed to manage risk successfully and the tendency of managers to oversimplify and dismiss an incident as a 'lack of competence'. To improve workers' competence there is a need for further training; however, the lack of investment in workers due to specialised trades, project schedules, and temporary contracts has already been discussed. There is also a lack of regulation of construction companies which fails to prevent a lack of competence leading to incidents.

You could set up a construction business tomorrow ... it's a low level of entry into the market, and that exposes people to risks and hazards that they're not capable of controlling. Safety Manager

This is exacerbated by a lack of resources and low profit margins. The role of the construction sector, as a provider of engineering solutions within other domains, means profit must be reaped from the supply chain and building processes. By employing the cheapest workers construction firms can reduce their outgoings, but these are often those with the lowest competence levels. Several participants spoke about the difficulties of resisting pressure from clients who were determined to keep costs down at the expense of employing, competent, qualified and safe personnel.

A more general lack of competence (for example, academic and social attainment) can also lead to risk-taking behaviours. Participants said workers chose construction because "they're well down the food chain when it comes to where they're going in life" (Safety Manager) and were incapable of doing anything else. From a systems perspective, it is important to understand why construction work attracts these workers: Although some trades are highlyskilled, the requirements for general labouring are quickly learnt; physical agility is prized over mental; and good social and language skills are rarely necessary. Construction suits 
workers with these traits, but this introduces management problems for those in charge. Again, these issues are embedded within the nature of construction work and the projectbased industry, but to improve safety it is important to understand why construction workers lack the necessary competence so training and regulation can focus on addressing these.

\section{'Cutting Corners'}

Shortcuts to save time and money were often seen as driven by laziness, but also symptomatic of a culture among construction workers to solve problems and prove themselves to be resourceful, capable and productive.

What we want people to do is stop and reflect, what they tend to do is to go in to automatic problem solving ... you know, "What would I get congratulated for, would I be congratulated for stopping work? Or would I be congratulated if I solve the problem?" Safety Manager

Participants felt workers had been conditioned by the customary lack of resources to rush and improvise, and there was a widespread expectation that prioritising cost and schedule over safety would be rewarded. Even in cases where projects were well-managed and safety budgeted for, it was difficult to change the attitudes of workers who were not used to work being open for discussion, projects being planned well, and companies being committed to workers’ wellbeing.

Pressure from clients - who were said to be more concerned with cost, schedule, and reputation than safe operation - was seen as the source of this: Participants provided examples of clients who appointed the cheapest firms, imposed penalties for contractors who took longer than planned, and sacked those involved in accidents to the dismay of the safety managers who could no longer learn from and improve upon the situation. These actions show a limited appreciation of construction processes, especially safety, and an unwillingness to take ownership of risk or invest in anything other than the end product. The subcontracted structure also creates opportunities for clients to pass the blame down to subcontractors, who in turn look to blame the primary contractor or client.

Low profit margins, compounded by a fear of litigation, can be seen to underpin corner cutting at all levels of the industry. Risk management is based on meeting the minimum standards for compliance: Safety policies were said to be reactive, disproportionate, not evidence based, rarely reviewed, and taking a broad-brush approach to cope with constant change. The extensive use of PPE, signage, and site rules to keep workers safe shows a reliance on the "the last line of defence" (Risk Consultant) rather than good planning and 
design. This profit-driven, and hence corner cutting, culture is inevitable in a competitive sector, and the most fundamental of the systemic issues it faces.

\section{High risk tolerance}

Most participants agreed construction workers had either an accepting or denying attitude towards risk, and some said they enjoyed the thrills and challenges of the work. In part, this is due to the potential for varied, physical, outdoor, and exciting work which attracts individuals with a risk tolerant personality. Often, these are young men who are flexible, hardworking, and problem solvers, and, although these traits are desirable for production, they tend to coincide with unpredictability, complacency and risk-taking. As discussed in the previous sections, the construction workforce is also known for its low levels of academic attainment, social skill, and economic privilege: Their low expectations can be seen to drive a need to achieve - cutting corners and saving money.

This is another clear example of the connection between risk tolerance and risk-taking at the frontline and the nature of construction as a distributed system which attracts unskilled and uncommitted workers who are difficult to manage. Risk tolerance is not a fixed trait but dependent upon pressures and incentives such as time, comfort, money, and reputation. These factors motivate workers to sacrifice safety and appear to have a high tolerance for risk, but in fact, these are initiated by systemic issues: Poor planning, tight schedules, poorly designed equipment and insensitive procedures; fear of litigation, and an expendable view of the workforce are all brought on by a lack of resources and stability. A high tolerance for risk can also be attributed to a lack of awareness, due to insufficient training, or disobedience, due to dissatisfaction, as already mentioned.

An improved understanding of the type of worker attracted to construction, and the pressures they face, can support safety managers' strategy to tackle unsafe acts. Greater empathy and autonomy could combat dissatisfaction, a balanced safety policy to maintain elements of construction which inspire workers and provide job satisfaction, and training to enhance risk awareness could all help lower workers' risk tolerance. However, more difficult to tackle are the organisational pressures which influence the culture of the organisation. Proving the roots of these problems identified here would provide evidence to challenge the view that workers are rebellious, negligent and complacent, and instead show they are scapegoats in a flawed system. 


\subsection{Summary of findings}

The findings provide an insight into the work of construction safety managers. It is clear they face not only the intrinsic hazards of a physical, dynamic work in challenging locations, but also managing a difficult demographic of workers, and competing with the pressures of an unstable and financially squeezed industry.

\section{Construction is just a big game of risk, companies go under all the time, because sort of tender} decisions are taking a risk- it is-it's what we're kind of used to. Academic

All three facets of the problem were explored - the work itself, the workforce, and its management. Construction is unstable, not only in terms of the workplace they are building, but its finances, workforce, and the systems in place to manage these. Its dynamic nature prevents the transfer of knowledge between projects and the implementation of consistent and well-designed safety measures (policies, training, culture, quality standards etc.). Lines of accountability become unclear in temporary organisations, leading to the shirking of safety responsibilities - by both the client and subcontractors - and a culture of blame and litigation. By exploring the wider organisational or industry-wide challenges it is possible to see the shaping influence these factors have on the structure and workforce of construction and the difficulties influencing safe behaviour.

\subsection{Systemic causes of risk in construction}

There is a clear need to tackle the roots of unsafe acts embedded within the construction industry; however, it is difficult to know how to approach change and who to hold responsible.

By using an STS lens on construction, the relationships between the issues which safety managers expressed have been explored to disentangle hazards from poor management, and poor worker attitudes from the industry-wide factors which attract and exacerbate these. This analysis provides evidence to challenge blame at the frontline: Many of the complaints about workers’ poor attitude (such as ‘silo working', cutting corners, high risk-tolerance and a lack of ownership, competence and engagement) can all be traced to systemic issues around the nature of construction work and pressures from the wider sociotechnical system. In light of this, the ConCa model (Gibb et al., 2006; Haslam et al., 2005) has been redrawn (Figure 5) to show how the site, technology and worker factors which combine to form accidents are framed within managerial and industrial originating and shaping influences. 


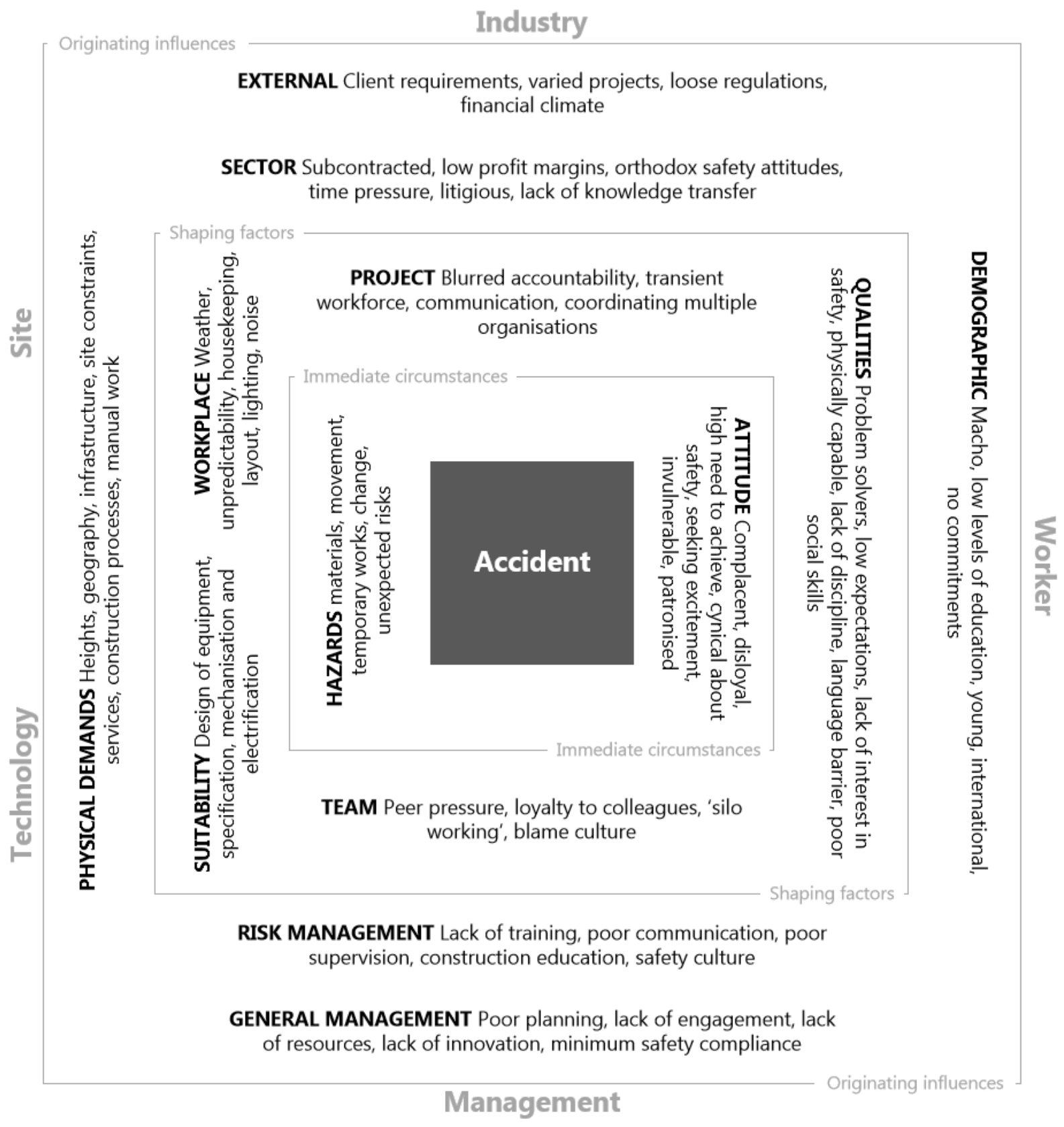

Figure 4 - ConCa +

Quantitatively, when asked about the causes of risk in construction, participants were more inclined to discuss the difficulties of managing a complex project - dealing with clients, subcontracting, and accountability - and worker attributes - a macho and complacent workforce This is in contrast to the original ConCA model (Figure 1) which elaborated more on the site and technology. Unlike accident reports which are reductionist and can be vulnerable to hindsight bias and (Dekker, 2002) (and which the original ConCA was based 
on), this study shows many managers are aware of the influence of a wide range of distal factors in the causation of accidents.

Taking a systems approach to interview analysis also provided an opportunity to explore the relationships between poor attitudes at the frontline and the industry-wide factors which attract and exacerbate these. While workers are often blamed for causing accidents because they lack interest in safety, work in silos, lack competence, cut corners, and have a high tolerance for risk, these traits can be traced to interrelated aspects of organisations and the industry. This approach generates new avenues for improvement which are explored under 'Recommendations and Future Work' (Section 4.5).

\subsection{Recommendations and future work}

The following research agenda summarises the opportunities highlighted by taking a systems thinking approach, going beyond increasing regulation, qualification, training, resources and length of contract which are often called for but difficult to realise effectively. It provides guidance for implementing and shaping some establishing safety methods and refocussing the way forward.

- Job enrichment research has shown that enlargement and rotation of roles can improve performance (Parker et al., 2017). Diversifying roles in construction could increase empathy, awareness, community, and the 'big picture' perspective, thus emphasising the value of each workers' roles in the project as a whole and inspiring pride in their work. Cross-trade training could provide increased competence at minimal expense to the company; however, it could reduce quality as skills are highly specialised and may be unpopular as workers are unlikely to want more information and responsibilities.

- “Learning legacy” programmes should be developed to improve transfer of knowledge between projects and awareness of innovation. These exist in high profile public sector projects in the UK, but there is a lack of support for smaller projects. Therefore, the programme should be extended to include a wide variety of projects; information must be brief and accessible; and manpower (particularly from architects, designers and engineers) allocated to seeking out and applying relevant innovation.

- Empowering and valuing workers is an underestimated aspect of risk management. Engaging with workers on risk management and respecting their expertise is 
particularly important in light of their low expectations and lack of loyalty. Collaboration would build vertical relationships, communication, trust, and protect against peer pressure.

- Risk management should involve workers on the frontline and be integrated into operations. Effort is required to change the perceptions of HSE staff as an enforcer of rules to a facilitator of ideas. Collaboration can help to combat dissatisfaction with insensitive procedures and equipment, but must be initiated in a way informed by the traits of workers - e.g. not academically minded, intimidated by professionals, not inclined to speak publicly, limited fluency and comprehension of local language, and influenced by peer pressure.

- Peer pressure could potentially be a powerful force for good given the need to build relationships quickly in a transient environment. Cultural programmes need persistence and repetition to account for constant change and counteract the pressures to prove their reputation or show-off to fit in.

- Adaptive safety has so far been touted as a solution for intractable industries; however, although the successes of well-managed projects prove construction is tractable (Bolt et al., 2012) it is not the most efficient to manage safety in a squeezed industry. Although the hazards are manageable the rate of change and unpredictability is not; thus, an adaptive approach could benefit an environment which - for reasons of time pressure, language barriers, low literacy levels, context on site, unstable processes, and change - does not cope well with paperwork.

\section{Limitations}

These finding are based on a modest sample of experts, and as such a degree of caution is required when generalising these to construction as a whole. Although this type of exploratory expert panel study, alongside STS analysis, does generate new theories and support novel opportunities for improvement in $\mathrm{OSH}$, future research is needed to validate these.

Another limitation of the study is that is focuses on the views of managers and policymakers; it does not include the views of workers which would help to validate their perception of risk-taking and evaluate the quality of the decision-making based on these 
influences. This is outside the scope of the current study and is another area where future work is needed.

\section{Conclusion}

The hazards of construction are embedded within building a physical output, both in terms of the practical processes needed to accomplish this and the temporary, undesignable nature of the workplace. This constant change makes managing risk difficult, not only within a project, but across the industry: The nature of the work - providing infrastructure for other businesses - means designs are unique, profit margins are extremely low, and work is suited to a dynamic network of specialist organisations contracted to specific aspects of the build. It is inevitable therefore that the physical nature of work and style of contract attracts workers who are uncommitted, physically capable, unafraid of hard work and seeking a career with plenty of variety. Unfortunately, these traits coincide with risk taking. Building for a client also means profit must be squeezed from the supply chain and building processes, leaving construction firms with little resource to invest in technologies which could improve processes, no time for change or learning, and no inclination to change because of the widespread acceptance that construction is risky. These top-down pressures from the client and bottom-up challenges from the workforce show why it is important to take a holistic approach to the system when managing safety.

Construction workers are perceived as having a high risk tolerance: This has been unpacked by exploring how and why attitudes vary within and between workers. Risk-taking behaviours depend firstly upon whether they are aware of the risk, secondly whether they perceive that risk as tolerable, and thirdly whether they feel the rewards are worth taking said risk. Many factors contribute to these, including the traits of the workforce; influences on their decision-making; and the pressures of the industry. In terms of supporting the managers this study shows a disparity between those who saw workers as negligent and disobedient and those with more enlightened views about distal or originating influences.

A systems thinking analysis of managers' perceptions lends support to the view that many of construction's problems are rooted within distal factors such as its transient workforce, financial constraints, and temporary organisations - products of a structure which is vital to providing unique outputs for a range of clients. Although this would be difficult to challenge, this paper provides advice for training and risk management which takes account of workers' traits and the pressures they face from the system. It also provides supporting evidence for 
emerging concepts in safety management: Collaborating with workers to show they are valued; integrating risk management in operations; increasing transfer of knowledge though 'learning legacy' programmes; cross-trade training to improve their 'big-picture perspective; and looking to adaptive safety to reduce paperwork and increase empowerment. 


\section{References}

Adams, J., 1995. Risk. UCL press, London.

Asilian-Mahabadi, H., Khosravi, Y., Hajizadeh, E., Hassanzadeh-Rangi, N., Bastani, H., Behzadan, A.H., 2014. Factors Influencing Unsafe Behaviors and Accidents on Construction Sites: A Review. Int. J. Occup. Saf. Ergon. 20, 111-125.

Atkinson, A.R., Westall, R., 2010. The relationship between integrated design and construction and safety on construction projects. Constr. Manag. Econ. 28, 1007-1017. doi:10.1080/01446193.2010.504214

Baiden, B.K., Price, A.D.F., 2011. The effect of integration on project delivery team effectiveness. Int. J. Proj. Manag. 29, 129-136. doi:10.1016/j.ijproman.2010.01.016

Behm, M., Schneller, A., 2013. Application of the Loughborough Construction Accident Causation model: a framework for organizational learning. Constr. Manag. Econ. 31, 580-595. doi:10.1080/01446193.2012.690884

Bieder, C., Bourrier, M., 2013. Trapping safety into rules: How desirable or avoidable is proceduralization?, Trapping Safety into Rules: How Desirable or Avoidable is Proceduralization? Ashgate Publishing Ltd.

Bolt, H.M., Haslam, R.A., Gibb, A.G., Waterson, P., 2012. Pre-conditioning for success.

Brace, C., Gibb, A.G., Pendlebury, M., Bust, P., 2009. Phase 2 Report: Health and safety in the construction industry: Underlying causes of construction fatal accidents - External research. London, UK.

Bryman, A., 2012. Social Research Methods, 4th ed. Oxford University Press, Oxford, UK.

Bureau of Labor Statistics, 2015. Illnesses, Injuries and Fatalities [WWW Document]. URL https://www.bls.gov/iif/ (accessed 3.22.17).

Chi, S., Han, S., 2013. Analyses of systems theory for construction accident prevention with specific reference to OSHA accident reports. Int. J. Proj. Manag. 31, 1027-1041. doi:10.1016/j.ijproman.2012.12.004

Choudhry, R.M., Fang, D., 2008. Why operatives engage in unsafe work behavior: Investigating factors on construction sites. Saf. Sci. 46, 566-584. doi:10.1016/j.ssci.2007.06.027

Dekker, S., Pitzer, C., 2016. Examining the asymptote in safety progress: a literature review. Int. J. Occup. Saf. Ergon. 22, 57-65. doi:10.1080/10803548.2015.1112104

Dekker, S.W.A., 2014. The bureaucratization of safety. Saf. Sci. 70, 348-357. doi:10.1016/j.ssci.2014.07.015

Dekker, S.W.A., 2002. Reconstructing human contributions to accidents: the new view on error and performance. J. Safety Res. 33, 371-385. doi:10.1016/S0022-4375(02)00032-4

Dekker, S.W. a., Hancock, P. a., Wilkin, P., 2012. Ergonomics and sustainability: towards an embrace of complexity and emergence. Ergonomics 139, 1-8.

doi:10.1080/00140139.2012.718799 
Donovan, S.-L., Salmon, P.M., Lenné, M.G., 2016. Leading with style: a literature review of the influence of safety leadership on performance and outcomes. Theor. Issues Ergon. Sci. 17, 423-442. doi:10.1080/1463922X.2016.1143986

du Toit, J.L., Mouton, J., 2012. A typology of designs for social research in the built environment. Int. J. Soc. Res. Methodol. 5579, 1-15. doi:10.1080/13645579.2012.657013

Dubois, A., Gadde, L.-E., 2002. Systematic combining: an abductive approach to case research. J. Bus. Res. 55, 553-560. doi:10.1016/S0148-2963(00)00195-8

Eason, K., 2008. Sociotechnical systems theory in the 21st Century: another half-filled glass?, in: Graves, D. (Ed.), Sense in Social Science: A Collection of Essays in Honour of Dr. Lisl Klein. Broughton, UK, pp. 123-134.

Eurostat, 2016. Accidents at work statisitics [WWW Document]. URL http://ec.europa.eu/eurostat/statistics-explained/index.php/Accidents_at_work_statistics (accessed 4.17.17).

Franz, B., Leicht, R., Molenaar, K., Messner, J., 2017. Impact of Team Integration and Group Cohesion on Project Delivery Performance. J. Constr. Eng. Manag. 143, 4016088. doi:10.1061/(ASCE)CO.1943-7862.0001219

Gibb, A., Haslam, R., Gyi, D., Hide, S., Duff, R., 2006. What causes accidents? Proc. ICE Civ. Eng. 159, 46-50.

Gibb, A., Hide, S., Haslam, R., Hastings, S., Abdelhamid, T.S., Everett, J.G., 2001. Identifying Root Causes of Construction Accidents. J. Constr. Eng. Manag. 127, 348349.

Given, L.M., 2008. The SAGE Encyclopedia of Qualitative Research Methods, 2nd ed. SAGE Publications Ltd, Thousand Oaks, CA. doi:10.4135/9781412963909

Glaser, B.G., Strauss, A.L., 1967. The Discovery of Grounded Theory: Strategies for Qualitative Research. Aldine Publishing Company, New York, NY.

Goh, Y.M., Askar Ali, M.J., 2016. A hybrid simulation approach for integrating safety behavior into construction planning: An earthmoving case study. Accid. Anal. Prev. 93, 310-318. doi:10.1016/j.aap.2015.09.015

Green, S.D., Kao, C., Larsen, G.D., 2010. Contextualist research: Iterating between methods while following an empirically grounded approach. J. Constr. Eng. Manag. 136, 117126. doi:10.1061/(ASCE)CO.1943-7862.0000027

Guest, G., Bunce, A., Johnson, L., 2006. How Many Interviews Are Enough? Field methods 18, 59-82. doi:10.1177/1525822X05279903

Guldenmund, F.W., 2010. (Mis)understanding Safety Culture and Its Relationship to Safety Management. Risk Anal. 30, 1466-80. doi:10.1111/j.1539-6924.2010.01452.x

Hale, A.R., Hovden, J., 1998. Managing culture: The third age of safety. A review of approaches to organisational aspects of safety health and environment., in: Williamson, A., Feyer, A.-M. (Eds.), Occupational Injury: Risk, Prevention and Intervention. CRC Press, London, pp. 129-167. 
Harvey, E.J., Waterson, P., Dainty, A.R.J., 2016a. Towards an alternative approach to safety in construction, in: Waterson, P., Sims, R., Hubbard, E.-M. (Eds.), Contemporary Ergonomics and Human Factors 2016. Chartered Institute of Ergonomics and Human Factors, Daventry, UK.

Harvey, E.J., Waterson, P., Dainty, A.R.J., 2016b. Applying HRO and resilience engineering to construction: Barriers and opportunities. Saf. Sci. doi:10.1016/j.ssci.2016.08.019

Haslam, R.A., Hide, S.A., Gibb, A.G.F., Gyi, D.E., Pavitt, T., Atkinson, S., Duff, A.R., 2005. Contributing factors in construction accidents. Appl. Ergon. 36, 401-15. doi:10.1016/j.apergo.2004.12.002

Hollangel, E., 2014. Safety-I and Safety-II: The Past and Future of Safety Management. Ashgate Publishing Limited, Farnham.

HSE, 2016. RIDDOR - Reporting of Injuries, Diseases and Dangerous Occurrences Regulations [WWW Document]. URL http://www.hse.gov.uk/statistics/tables/index.htm\#riddor (accessed 4.3.17).

HSE, 2014. Health and Safety in Construction in Great Britain, 2014.

HSE, 2004. Recidivist risk takers who work at a height [WWW Document]. URL http://www.hse.gov.uk/research/rrpdf/rr201.pdf

Lingard, H., 2013. Occupational health and safety in the construction industry. Constr. Manag. Econ. 31, 505-514. doi:10.1080/01446193.2013.816435

Lingard, H., Hallowell, M., Salas, R., Pirzadeh, P., 2017. Leading or lagging? Temporal analysis of safety indicators on a large infrastructure construction project. Saf. Sci. 91, 206-220. doi:10.1016/j.ssci.2016.08.020

Lingard, H., Rowlinson, S., 2005. Occupational Health and Safety in Construction Project Management. Spon Press, Oxon, UK.

Long, R., 2012. For The Love of Zero. Scotoma Press, Kambah, ACT.

Love, P.E.D., Ding, L., Luo, H., 2016. Systems thinking in workplace safety and health in construction: Bridging the gap between theory and practice. Accid. Anal. Prev. 93, 227229. doi:10.1016/j.aap.2016.05.026

NIOSH, 2011. Construction Safety and Health [WWW Document]. URL http://www.cdc.gov/niosh/topics/construction/ (accessed 7.6.16).

Onwuegbuzie, A.J., Leech, N.L., 2005. On Becoming a Pragmatic Researcher: The Importance of Combining Quantitative and Qualitative Research Methodologies. Int. J. Soc. Res. Methodol. 8, 375-387. doi:10.1080/13645570500402447

Oswald, D., Sherratt, F., Smith, S., 2014. Exploring factors affecting unsafe behaviours in construction, in: Proceedings 29th Annual Association of Researchers in Construction Management Conference, ARCOM 2013. Association of Researchers in Construction Management, pp. 335-344.

Parker, S.K., Van den Broeck, A., Holman, D., 2017. Work Design Influences: A Synthesis of Multilevel Factors that Affect the Design of Jobs. Acad. Manag. Ann. 11. 
Pidgeon, N., O’Leary, M., 2000. Man-made disasters: why technology and organizations (sometimes) fail. Saf. Sci. 34, 15-30. doi:10.1016/S0925-7535(00)00004-7

Rabionet, S.E., 2011. How I Learned to Design and Conduct Semi-structured Interviews: An Ongoing and Continuous Journey. Qual. Rep. 16, 563-566.

Read, G.J.M., Salmon, P.M., Lenné, M.G., Stanton, N.A., 2015. Designing sociotechnical systems with cognitive work analysis: putting theory back into practice. Ergonomics 58, 822-851. doi:10.1080/00140139.2014.980335

Reason, J., 2000. Human Error: Models and Management. Br. Med. J. 320, 768-770.

Saurin, T.A., 2016. Safety inspections in construction sites: A systems thinking perspective. Accid. Anal. Prev. 93, 240-250. doi:10.1016/j.aap.2015.10.032

Sawacha, E., Naoum, S., Fong, D., 1999. Factors affecting safety performance on construction sites. Int. J. Proj. Manag. 17, 309-315. doi:10.1016/S0263-7863(98)000428

Scholz, R.W., Tietje, O., 2002. Embedded Case Study Methods: Integrating Quantitative and Qualitative Knowledge. Sage Publications, Inc., Thousand Oaks, CA.

Shannon, H.S., Robson, L.S., Guastello, S.J., 1999. Methodological criteria for evaluating occupational safety intervention research. Saf. Sci. 31, 161-179. doi:10.1016/S09257535(98)00063-0

Sherratt, F., Dainty, A.R.J., 2017. UK construction safety: a zero paradox? Policy Pract. Heal. Saf. 1-9. doi:10.1080/14773996.2017.1305040

Shin, M., Lee, H.-S., Park, M., Moon, M., Han, S., 2014. A system dynamics approach for modeling construction workers' safety attitudes and behaviors. Accid. Anal. Prev. 68, 95-105. doi:10.1016/j.aap.2013.09.019

Stringer, J., 1967. Operational Research for Development. J. Oper. Res. Soc. 18, 105-120. doi:10.1057/palgrave.jors.2600047

Swuste, P., 2008. "You will only see it, if you understand it" or occupational risk prevention from a management perspective. Hum. Factors Ergon. Manuf. 18, 438-453. doi:10.1002/hfm.20101

Taleb, N.N., 2008. The Black Swan: The Impact of the Highly Improbable. Penguin Books, London, UK.

Turner, B.A., Pidgeon, N.F., 1997. Man-made Disasters, 2nd ed. Butterworth-Heinemann, Oxford, UK.

Walliman, N., 2011. Your Research Project, 3rd ed. Sage, London, UK.

Waterson, P., 2015. Sociotechnical design of Work Systems, in: Wilson, J.R., Sharples, S. (Eds.), Evaluation of Human Work. CRC Press, Boca Raton, FL, pp. 753-772.

Waterson, P., Robertson, M.M., Cooke, N.J., Militello, L., Roth, E., Stanton, N.A., 2015. Defining the methodological challenges and opportunities for an effective science of sociotechnical systems and safety. Ergonomics 58, 1-35. 
doi:10.1080/00140139.2015.1015622

Wilde, G.J.S., 1982. The Theory of Risk Homeostasis: Implications for Safety and Health. Risk Anal. 2, 209-225. doi:DOI: 10.1111/j.1539-6924.1982.tb01384.x

Wilson, J.R., 2014. Fundamentals of systems ergonomics/human factors. Appl. Ergon. 45, 5- 


\section{Appendix 1}

\section{Interview Schedule}

Background

1) Tell me about your role and previous experience

a. Current position

b. Previous experience

\section{Risk Management in Construction}

2) What makes construction so hazardous?

3) What makes managing risk difficult?

Safe and unsafe workers

4) How do construction workers view risk?

a. Describe their attitude

b. What has given you this impression?

5) Why do some workers behave unsafely? 